\title{
Qualidade e viabilidade de probióticos comercializados em farmácias magistrais de
}

\section{Cascavel-PR}

\author{
Quality and viability of probiotics sold in handling pharmacies in Cascavel-PR \\ Calidad y viabilidad de los probióticos vendidos en manipulación de farmacias en Cascavel-PR
}

Recebido: 15/10/2021 | Revisado: 22/10/2021 | Aceito: 24/10/2021 | Publicado: 26/10/2021

\author{
Ellen Cristina de Souza Hell da Silva \\ ORCID: https://orcid.org/0000-0001-7918-4540 \\ Centro Universitário Assis Gurgacz, Brasil \\ E-mail: ellencristinahell@gmail.com \\ Suzana Bender \\ ORCID: https://orcid.org/0000-0001-8913-1952 \\ Centro Universitário Assis Gurgacz, Brasil \\ E-mail: suzanabender@hotmail.com
}

\begin{abstract}
Resumo
Para um produto ser considerado probiótico, este deve apresentar células viáveis, na dose descrita no rótulo, até o prazo de validade e quando manipulado na forma de cápsulas deve seguir critérios de qualidade estabelecidos na legislação. Portanto, o objetivo desse estudo foi avaliar a qualidade das cápsulas manipuladas com probióticos, bem como verificar a viabilidade dos microrganismos em três farmácias magistrais, da cidade de Cascavel-PR. Analisou-se a rotulagem dos produtos, o peso médio e a viabilidade celular. Identificaram-se os microrganismos através das características morfotintoriais e prova da catalase. Apenas o rótulo da farmácia 2 apresentou a descrição preconizada pela legislação, entretanto, apesar do prazo de validade proposto, o laudo do fabricante apontou que uma das matérias-primas estava vencida. O peso médio estava em conformidade em todas as farmácias. Quanto à viabilidade celular, ocorreram diferenças na repetição e entre as farmácias. Na repetição, a farmácia 1 não apresentou crescimento de células viáveis e a Farmácia 2, demonstrou uma perda da viabilidade quando comparada ao primeiro ensaio. A farmácia 3 quando comparada as outras farmácias, demonstrou um crescimento satisfatório. Esse estudo demonstrou não haver um controle de qualidade rigoroso para a manipulação de cápsulas contendo probióticos, comprometendo a qualidade e eficácia do produto. Dessa forma, se torna necessário padronizar estes produtos segundo sua concentração, prazo de validade e excipientes utilizados, de modo a garantir o melhor tratamento para o paciente.
\end{abstract}

Palavras-chave: Viabilidade microbiana; Probióticos; Boas práticas de manipulação.

\begin{abstract}
To be considered probiotic, a product must present viable cells, at the dose described on the label, until the expiry date and when handled in the form of capsules must follow the quality criteria set out in the legislation. Therefore, the aim of this study was to evaluate the quality of capsules handled with probiotics, as well as to verify the viability of microorganisms in three masterful pharmacies in the city of Cascavel-PR. The labeling of products, the average weight and cell viability. Microorganisms were identified using morpho-tinrial characteristics and catalase test. Only the pharmacy label 2 presented the description recommended by the legislation, however, despite the proposed shelf life, the manufacturer's report indicated that one of the raw materials was expired. The average weight was in compliance in all pharmacies. Regarding cell viability, there were differences in repetition and between pharmacies. In the repetition, pharmacy 1 did not show viable cell growth and Pharmacy 2 demonstrated a loss of viability when compared to the first trial. Pharmacy 3, when compared to other pharmacies, showed satisfactory growth. This study demonstrated that there is no strict quality control for the manipulation of capsules containing probiotics, compromising the quality and efficacy of the product. Thus, it is necessary to standardize these products according to their concentration, shelf life and excipients used, in order to ensure the best treatment for the patient.
\end{abstract}

Keywords: Microbial viability; Probiotics; Good handling practices.

\section{Resumen}

Para que un producto sea considerado probiótico, debe presentar células viables, a la dosis descrita en la etiqueta, hasta la fecha de vencimiento y cuando se manipule en forma de cápsulas debe seguir los criterios de calidad establecidos por la legislación. Por tanto, el objetivo de este estudio fue evaluar la calidad de las cápsulas manipuladas con probióticos, así como verificar la viabilidad de los microorganismos en tres farmacias maestras de la ciudad de Cascavel-PR. Se analizó el etiquetado del producto, el peso medio y la viabilidad celular. Los microorganismos fueron identificados mediante características morfo-tintoriales y prueba de catalasa. Solo la etiqueta de la farmacia 2 presentaba la descripción recomendada por la legislación, sin embargo, a pesar de la fecha de vencimiento propuesta, el informe del 
fabricante indicaba que una de las materias primas había vencido. El peso medio se cumplió en todas las farmacias. En cuanto a la viabilidad celular, hubo diferencias en la repetición y entre farmacias. En repetición, la Farmacia 1 no mostró crecimiento celular viable y la Farmacia 2 mostró una pérdida de viabilidad en comparación con el primer ensayo. La Farmacia 3, en comparación con otras farmacias, mostró un crecimiento satisfactorio. Este estudio demostró que no existe un estricto control de calidad para el manejo de cápsulas que contienen probióticos, comprometiendo la calidad y efectividad del producto. Por ello, es necesario estandarizar estos productos según su concentración, fecha de caducidad y excipientes utilizados, con el fin de asegurar el mejor tratamiento para el paciente.

Palabras clave: Viabilidad microbiana; Probióticos; Buenas prácticas de manejo.

\section{Introdução}

A disbiose intestinal é um termo utilizado para quando há um desequilibro da flora intestinal, problema que atualmente acomete muitas pessoas. Ela está relacionada a diversas condições de saúde como doenças cardiovasculares, esteatose hepática, obesidade, colite ulcerosa crônica, diarreia associada a antibióticos, doença de Crohn, síndrome do intestino irritável, entre outras (Troche, 2020; Chamberlain, et al., 2019; Kim, et al., 2019). Diante disso, nas últimas décadas a modulação da microbiota por meio de probióticos, têm se tornado uma alternativa para auxiliar no restabelecimento da condição da microbiota normal (Troche, 2020; Mazzantini, et al., 2021).

A definição de probiótico mais utilizada mundialmente é que eles são "microrganismos vivos que, quando administrados em quantidades adequadas, conferem um benefício à saúde do hospedeiro" (Hill et al., 2014). Para ser considerado probiótico não basta ser apenas um microrganismo com vida, é necessário ter comprovação científica que a cepa utilizada tem efeitos benéficos a saúde (Hill, et al., 2014; Kolacek, et al., 2017).

Os probióticos são classificados pelo seu gênero, espécie e a cepa correspondente. Existem mais de 200 espécies do gênero Lactobacillus sp. e elas são divididas em 15 grupos (Duar, et al., 2017; Bravo et al., 2021). A espécies desse gênero são classificados como bactérias lácticas e são bastonetes Gram-positivos, anaeróbicos obrigatórios e facultativos, catalasenegativos, não formadores de esporos e não são patogênicos (Nazir, et al., 2020; Chamberlain, et al., 2019).

A viabilidade dessas bactérias lácticas pode ser afetada por danos as células, causado por espécies reativas de oxigênio e subprodutos tóxicos de oxigênio (Feng \& Wang, 2020), além de outros fatores, como armazenamento incorreto e a umidade (Fenster, et al., 2019). Sabe-se que para um probiótico ser benéfico e eficaz para o uso deve ser utilizado na dose correta para produzir o efeito desejado (Shehata, et al., 2019). Embora ainda existam alguns estudos que divergem quanto a concentração mínima efetiva, geralmente é aceita uma concentração mínima de 106 UFC/mL ou grama e um total de 108 a 109 microrganismos para ingestão diária (Nazir, et al., 2020).

Garantir que essa concentração efetiva permaneça até o prazo de validade é um grande desafio para os fabricantes, pois nesse processo diversos fatores representam um desafio na produção, como o design, desenvolvimento, fabricação, comercialização e gerenciamento do ciclo de vida. Alguns problemas foram identificados recentemente quanto a comercialização de produtos contendo probióticos, como a quantidade de células viáveis inferior ao declarado no rótulo (Morovic, et al., 2016; Jackson, et al., 2019). Portanto, é fundamental verificar se a quantidade de microrganismos viáveis se mantém durante o armazenamento do probiótico. Todo produto comercializado contendo probióticos precisa descrever a cepa, a contagem em unidades formadas de colônia e também os benefícios a saúde (Shehata, et al., 2019; Morovic, et al., 2016; Terpou, et al., 2019).

Dessa forma existe a preocupação com a qualidade dos produtos que contem esses microrganismos. Dentre as formas de comercialização de probióticos encontradas no mercado, as formulações magistrais representam um mercado que precisa ser submetido a um controle de qualidade mais rigoroso (Mazzantini, et al., 2021).

Nas farmácias magistrais, os probióticos quando vendidos estarão na forma de sachês ou cápsulas. As cápsulas gelatinosas duras são a forma farmacêutica mais utilizadas, devido a facilidade de produção, versatilidade na escolha dos ativos, além de ter um baixo custo. O preenchimento das cápsulas é realizado em grande parte das farmácias através de encapsuladoras 
manuais (Ferreira, 2008).

Excipientes podem auxiliar e facilitar o enchimento das cápsulas e eles devem ser escolhidos com base no ativo da formulação prescrita. De forma a contribuir, excipientes como os prebióticos e minerais podem aumentar a estabilidade dos probióticos. Estes excipientes devem ser validados e avaliados dentro de uma formulação final, para confirmar se são compatíveis com o probiótico durante o período de armazenamento do produto acabado (Grumet, et al., 2020).

Após a escolha do excipiente, outro fator importante é que o conteúdo de todas as cápsulas deve estar homogêneo, de forma a garantir a mesma dose do ativo. A homogeneidade das cápsulas está relacionada as habilidades técnicas do operador responsável por esse processo. Isso pode influenciar na qualidade do produto acabado, portanto, o controle de qualidade de cápsulas manipuladas é essencial (Ferreira, 2008).

Para capsulas preparadas nas farmácias magistrais, a Resolução Diretoria Colegiada (RDC) no 67 de 8 de outubro de 2007 da ANVISA estabelece como testes mínimos de controle de qualidade os ensaios de descrição, aspecto, caracteres organolépticos, peso médio. Estes testes devem ser realizados conforme a Farmacopeia Brasileira ou outro Compêndio Oficial reconhecido pela Anvisa (Brasil, 2007).

Portanto, este estudo teve por objetivo avaliar a qualidade das cápsulas manipuladas com probióticos, bem como verificar a viabilidade dos microrganismos em três farmácias magistrais da cidade de Cascavel-PR.

\section{Metodologia}

O presente estudo trata-se de uma pesquisa descritiva, com analise experimental, baseada na abordagem qualiquantitativa (Pereira, et al., 2018), em que foram analisadas três fórmulas produzidas em farmácias magistrais da cidade de Cascavel-PR, com 30 cápsulas contendo uma concentração de 109 UFC de probióticos por cápsula.

\subsection{Avaliação do rótulo dos probióticos manipulados em diferentes farmácias de manipulação}

A avaliação do rótulo foi realizada de forma descritiva observando os itens obrigatórios constantes na Resolução Diretoria Colegiada (RDC) no 67 de 8 de outubro de 2007 (Brasil, 2007).

\subsection{Peso médio das cápsulas}

Para verificar se o conteúdo das cápsulas estava distribuído de forma homogênea, foi realizado o teste de peso médio. Foram pesadas individualmente 20 cápsulas de cada produto. Logo em seguida, o conteúdo foi removido de forma total e as cápsulas vazias foram pesadas. Através dos valores, foi determinado o peso do conteúdo de cada cápsula pela diferença de peso entre a cápsula cheia e a vazia, determinando assim o peso médio do conteúdo das cápsulas (Brasil, 2019).

\subsection{Ativação do Lactobacillus sp}

A ativação foi realizada de forma adaptada com base na metodologia Schmitt (2014). O conteúdo de uma cápsula de Lactobacillus sp de cada farmácia foi transferido individualmente para tubos contendo 9mL de caldo MRS. Eles foram homogeneizados e incubados por um período de $24 \mathrm{~h}$ em jarra de anaerobiose a $37 \pm 1^{\circ} \mathrm{C}$.

\subsection{Avaliação da viabilidade celular do Lactobacillus sp}

A avaliação da viabilidade foi realizada conforme metodologia de Schmitt (2014). Após 24h de incubação foi realizada centrifugação dos tubos a 5000rpm por 5 minutos. Descartou-se o sobrenadante e o sedimento foi ressuspenso em $10 \mathrm{~mL}$ de solução salina fosfatada tamponada, logo após, realizou-se homogeneização em vórtex, seguida de centrifugação. Este procedimento foi realizado por 3 vezes, até completa eliminação do caldo MRS. 
Para ressuspender o sedimento, foi acrescentado $9 \mathrm{~mL}$ de de salina fosfatada tamponada e a partir desta suspensão foram realizadas oito diluições sucessivas. A determinação da viabilidade celular foi realizada pela técnica de semeadura em profundidade utilizando o meio ágar MRS (Man Rogosa e Sharp). A incubação foi realizada por um período de $48 \mathrm{~h}$ em jarra de anaerobiose a $37 \pm 1^{\circ} \mathrm{C}$. As análises foram realizadas em triplicata, com uma repetição. Os resultados foram expressos em UFC por cápsula.

\subsubsection{Caracterização morfo-tintorial e teste da catalase}

A fim de verificar se a formulação adquirida continha Lactobacillus sp, foram realizadas a prova da catalase e a avaliação das características morfo-tintoriais do microrganismo. A coloração de Gram foi realizada conforme a metodologia de Tripathi e Sapra (2021). Uma cultura de Lactobacillus sp foi fixada na lâmina e uma gota de salina previamente esterilizada acrescentada. Após a lâmina estar completamente seca, adicionou-se cristal violeta e depois de 60 segundos foi realizado o enxágue da lâmina em água corrente. Em seguida o iodo foi acrescentado e após 60 segundos será realizado novamente o enxágue. Após esse processo, adicionou-se um pouco descorante na lâmina e novamente foi realizado o enxague. A fucsina foi adicionada a lâmina e após 40 segundos, foi realizado o enxague da lâmina em água corrente. Após estar completamente seca, foi realizado a leitura em um microscópio com a objetiva x100 (imersão).

O teste de catalase foi realizado conforme metodologia de Brasil, (2013). Em uma lâmina, foi colocado uma gota de peróxido de hidrogênio 3\%. Com o auxílio de uma alça bacteriológica, foi colocado uma colônia na lâmina, de forma a agregar a colônia em estudo na gota de peróxido de hidrogênio.

\section{Resultados e Discussão}

\subsection{Avaliação do Rótulo}

Os dados observados de forma descritiva constantes nos rótulos das farmácias avaliadas estão demonstrados na Tabela 1 a seguir.

Tabela 1 - Resultados obtidos através da análise do rótulo de cápsulas contendo probiótico manipulado em diferentes farmácias magistrais em Cascavel - PR.

\begin{tabular}{|c|c|c|c|}
\hline Rótulo & Farmácia 1 & Farmácia 2 & Farmácia 3 \\
\hline Nome do prescritor & Não conforme & Em conformidade & Não conforme \\
\hline Nome do paciente & Em conformidade & Em conformidade & Em conformidade \\
\hline $\mathrm{N}^{\mathrm{o}}$ de registro da formulação & Em conformidade & Em conformidade & Em conformidade \\
\hline Data da manipulação & Em conformidade & Em conformidade & Em conformidade \\
\hline Prazo de validade & Em conformidade & Em conformidade & Em conformidade \\
\hline Quantidade dos componentes da formulação** & Em conformidade & Em conformidade & Em conformidade \\
\hline $\mathrm{N}^{\mathrm{o}}$ de unidades & Em conformidade & Em conformidade & Em conformidade \\
\hline Posologia & Em conformidade & Em conformidade & Em conformidade \\
\hline Identificação da farmácia & Em conformidade & Em conformidade & Em conformidade \\
\hline C.N.P.J. & Em conformidade & Em conformidade & Em conformidade \\
\hline Endereço completo & Em conformidade & Em conformidade & Em conformidade \\
\hline Farmacêutico responsável & Em conformidade & Em conformidade & Em conformidade \\
\hline $\mathrm{N}^{\mathrm{o}}$ de registro no $\mathrm{CRF}$ & Em conformidade & Em conformidade & Em conformidade \\
\hline
\end{tabular}

*Dados avaliados segundo RDC 67/2007 item 12.1.

** Concentração do probiótico.

Fonte: Autores. 
Conforme observado na tabela 01, a maior parte dos critérios listados na RDC 67/2007 estão de acordo para todas as farmácias. O único item não conforme foi o nome do prescritor que conforme a RDC 67 item 12.1 deve ser obrigatório visto que as formulações só podem ser preparadas mediante prescrição.

Ao avaliar a necessidade de etiquetas com advertências complementares impressas no rótulo conforme no item 12.3 da RDC 67/2007, apenas a Farmácia 3 descreveu cuidados a serem tomados quanto aos fatores ambientais, "Manter fora de fonte de luz, calor e umidade". Essa etiqueta complementar auxilia o consumidor a armazenar o produto de maneira adequada, de forma a garantir uma melhor viabilidade do microrganismo. Ao considerar que na região oeste do Paraná, durante o verão as temperaturas ultrapassam os $30^{\circ} \mathrm{C}$, os probióticos terão sua viabilidade alterada uma vez que no laudo dos produtos os mesmos devem ser mantidos abaixo de $20^{\circ} \mathrm{C}$. Jackson, et al., (2019), descreveram em seu estudo que fatores como a umidade e a temperatura podem afetar a viabilidade do probiótico, dessa forma seria necessário acrescentar essa etiqueta.

Outro fato observado foi o prazo de validade que foi diferente nos três produtos, entretanto, com a mesma data de fabricação. A Farmácia 1 colocou no rótulo o prazo de validade para 60 dias, enquanto a Farmácia 2 para 90 dias e a Farmácia 3 para 120 dias. A RDC n ${ }^{\circ} 67$ de 2007 descreve que o prazo de validade deve ser estabelecido conforme os testes de estabilidade, porém, destacou que preferencialmente o prazo de validade deve ser vinculado ao período de tratamento do paciente (Brasil, 2007). Desta forma pode-se concluir que as diferentes datas de validade podem estar relacionadas a estabilidade individual da matéria prima adquirida de diferentes fornecedores.

O prazo de validade conferido a cada produto analisado foi verificado com base no laudo do fornecedor do probiótico. Para preparações magistrais sólidas, o prazo de validade deve ser estabelecido de forma a considerar como a natureza de cada ingrediente se comporta, a combinação entre eles, a forma farmacêutica final, o modo como foi manipulado, a embalagem utilizada e as condições de armazenamento (Thompson \& Davidow, 2013).

Se o produto for embalado em um frasco hermeticamente fechado, armazenado sob temperatura controlada, ao abrigo da luz, o prazo de validade para matérias primas advindas de indústria, não deve ser mais que $25 \%$ do tempo restante até a data de validade do produto ou de seis meses, o que ocorrer primeiro (Thompson \& Davidow, 2013).

Com base nesta análise foi observado que apenas a Farmácia 1 estava em conformidade com esse critério. A farmácia 2 e 3 descreveram no rótulo um prazo de validade que não foi estabelecido conforme a estabilidade do probiótico. A Farmácia 2 estabeleceu no rótulo do produto manipulado o prazo de validade para outubro de 2021, e no laudo do fabricante, o insumo ativo venceu em setembro de 2021. A farmácia dispensou cápsulas contendo probióticos vencidos. Já no rótulo do probiótico da Farmácia 3, o prazo de validade estipulado foi para um período de 120 dias, considerando que o período não deve ser superior a $25 \%$, a validade deveria ser no máximo de 90 dias, conforme o laudo do fornecedor. Dessa forma não ficou claro o critério que as farmácias 2 e 3 utilizaram para estabelecer o prazo de validade, comprometendo assim a segurança e eficácia do produto.

\subsection{Peso médio}

Os resultados obtidos na avaliação do peso médio das cápsulas estão apresentados na Tabela 2.

Tabela 2 - Peso médio das cápsulas adquiridas em diferentes farmácias de manipulação em Cascavel - PR.

\begin{tabular}{llll}
\hline & Farmácia 1 & Farmácia 2 & Farmácia 3 \\
\hline Peso médio * & $169,1 \mathrm{mg}$ & $171,35 \mathrm{mg}$ & $101.15 \mathrm{mg}$ \\
Desvio padrão & $3,60 \mathrm{mg}$ & $5,8 \mathrm{mg}$ & $2,96 \mathrm{mg}$ \\
Desvio padrão relativo & $2,13 \%$ & $3,38 \%$ & $2,93 \%$ \\
\hline
\end{tabular}

*A análise do peso médio foi realizada com 15 cápsulas de cada farmácia.

Fonte: Autores. 
As três farmácias apresentaram resultados em conformidade com a $6^{a}$ edição da Farmacopeia Brasileira. Os resultados demonstram que o conteúdo das cápsulas estava distribuído de forma uniforme. $\mathrm{O}$ valor de desvio padrão relativo das três farmácias conforme descrito na tabela 2 foi inferior a 4\%, assim como está preconizado pela literatura (Brasil, 2019).

Em um estudo realizado por Oliveira, et al., (2014), foi avaliado o peso médio de cápsulas manipuladas de nimesulida e os resultados obtidos também estavam em conformidade com a Farmacopeia. O mesmo resultado foi encontrado em uma pesquisa realizada por Andrade, Carvalho e Freitas (2013), onde foi avaliado o peso médio das cápsulas de fluoxetina manipuladas.

Segundo o item 9.1.2 da RDC 67/2007, os resultados dos ensaios de controle de qualidade do produto acabado, como o peso médio, devem ser registrados na ordem de manipulação. O farmacêutico é responsável por verificar se estes resultados estão em conformidade e aprovar ou não o produto para ser dispensado. Caso ocorra a reprovação do produto, é realizado uma nova preparação que esteja em conformidade para ser dispensada ao cliente (Brasil, 2007). Conclui-se então que este item estará em conformidade para todas as farmácias uma vez que é obrigatória sua verificação antes da dispensação.

\subsection{Avaliação da viabilidade dos microrganismos}

. Sabe-se que para um probiótico produzir benefícios ele precisa ter uma quantidade mínima de células viáveis. Através dos resultados obtidos, foi possível determinar a quantidade de células microbianas viáveis contidas em uma cápsula, conforme descrito na Tabela 3 a seguir.

Tabela 3. Unidades formadoras de colônias de Lactobacillus sp da Farmácia 1.

\begin{tabular}{lll}
\hline Amostras & UFC/cápsula & Repetição* \\
\hline Placa 1 & $2,40 \times 10^{10}$ & Não houve crescimento \\
Placa 2 & $2,63 \times 10^{10}$ & Não houve crescimento \\
Placa 3 & $2,04 \times 10^{10}$ & Não houve crescimento \\
\hline Valor médio & $1,17 \times 10^{10}$ & \\
Desvio padrão & $1,19 \times 10^{10}$ & \\
Desvio padrão relativo & $101,06 \%$ & \\
\hline
\end{tabular}

*Ensaio realizado em triplicata com uma repetição.

Fonte: Autores.

A farmácia 1, em uma primeira avaliação de resultados, apresentou crescimento dos probióticos em diferentes quantidades do que está declarado no rótulo ( $10^{9}$ UFC por cápsula). Foi observado em um estudo realizado por Fenster, et al., (2019), que muitas empresas costumam colocar quantidades acima do descrito no rótulo para compensar as potenciais perdas durante o período de armazenamento.

Em uma pesquisa com 10 produtos contendo probióticos realizada por Celandroni et al., (2018), 3 produtos apresentaram uma quantidade de células viáveis acima do declarado no rótulo dos produtos. Em outros estudos conduzidos por Weise e Martins (2011) e Schimitt et al., (2018) os autores observaram que quantidade declarada no rótulo do produto era inferior a encontrada na análise da viabilidade. Porém, mesmo que acima, deveria estar descrito no rótulo para informar o consumidor. Entretanto, quando realizada a repetição da análise de viabilidade para farmácia 1, não houve crescimento, conforme demonstrado na Tabela 3. Este fato pode ter ocorrido por não existirem microrganismos presentes naquela cápsula. No estudo realizado por Weise e Martins (2011), em um dos quinze produtos que foram analisados, não houve crescimento de células viáveis em nenhuma das repetições. Para confirmar o resultado, o teste foi realizado novamente com outras cápsulas e a ausência de microrganismos foi confirmada. 
Outra explicação para não ter ocorrido o crescimento na repetição da Farmácia 1, foi pela complexibilidade da metodologia empregada no crescimento de microrganismos, uma vez que este pode sofrer alterações por diversos fatores como pH, capacidade tampão, espécies reativas de oxigênio e a intensidade de homogeneização. Jackson et al., (2019), observaram que os fatores acima citados, podem interferir na quantidade de células viáveis ao analisar a viabilidade de produtos com probióticos.

Tabela 4. Unidades formadoras de colônias de Lactobacillus sp da Farmácia 2.

\begin{tabular}{lll}
\hline Amostras & UFC/cápsula & Repetição* \\
\hline Placa 1 & $3,15 \times 10^{10}$ & $0,9 \times 10^{9}$ \\
Placa 2 & $3,70 \times 10^{10}$ & $3,6 \times 10^{9}$ \\
Placa 3 & $3,28 \times 10^{10}$ & $2,6 \times 10^{9}$ \\
\hline Valor médio & $1,80 \times 10^{10}$ & \\
Desvio padrão & $1,58 \times 10^{10}$ & \\
Desvio padrão relativo & $87,49 \%$ & \\
\hline
\end{tabular}

*Ensaio realizado em triplicata com uma repetição.

Fonte: Autores.

Conforme foi observado na Tabela 4, também houve diferença na Farmácia 2 quanto a quantidade declarada no rótulo e a quantidade de microrganismos que cresceram. Esta diferença pode ter ocorrido pelos mesmos critérios já discutidos para a Farmácia 1.

Quando comparado o crescimento dos microrganismos da farmácia 2 e a repetição da análise, observou-se uma diferença no crescimento dos microrganismos. Este fato pode ter ocorrido devido a homogeneização dos probióticos e dos excipientes na manipulação da cápsula. Segundo Ferreira (2008), a homogeneização é uma etapa fundamental para distribuir o ativo de forma igual em cada cápsula. Outro motivo, pode ser devido a uma perda da viabilidade, conforme demonstrado em um estudo realizado por Kolacek, et al., (2017), onde a quantidade de células viáveis variou em cada comprimido e diminuiu em função do tempo, até o prazo de validade.

Tabela 5. Unidades formadoras de colônias de Lactobacillus sp da Farmácia 3.

\begin{tabular}{lll}
\hline Amostras & UFC/cápsula & Repetição \\
\hline Placa 1 & $5,44 \times 10^{10}$ & $6,54 \times 10^{10}$ \\
Placa 2 & $6,32 \times 10^{10}$ & $2,79 \times 10^{10}$ \\
Placa 3 & $5,97 \times 10^{10}$ & $4,43 \times 10^{10}$ \\
\hline Valor médio & $5,24 \times 10^{10}$ & \\
Desvio padrão & $1,29 \times 10^{10}$ & \\
Desvio padrão relativo & $24,71 \%$ & \\
\hline
\end{tabular}

*Ensaio realizado em triplicata com uma repetição.

Fonte: Autores.

Na Tabela 5, a quantidade de microrganismos da Farmácia 3 foi ainda maior quando comparada a Farmácia 1 e 2. Apesar de apresentar uma quantidade de células acima do que está declarado no rótulo, essa foi a única farmácia que na repetição apresentou resultados mais próximos do primeiro ensaio, conforme demostrado no desvio padrão relativo (24\%). O que demonstrou maior padronização na manipulação das cápsulas.

Ao comparar a viabilidade dos microrganismos entre as farmácias 1, 2 e 3, observou-se diferença na quantidade de UFC por cápsula. Essa diferença na viabilidade dos microrganismos pode ter ocorrido em função do excipiente utilizado, do fornecedor dos probióticos e da forma como a matéria prima foi transportada do fornecedor até as farmácias. 
Conforme dados fornecidos pelas farmácias magistrais, quanto aos excipientes, a Farmácia 1 utilizou Celulose Microcristalina, enquanto a Farmácia 2 fez uso do fruto-oligossacarídeo e a Farmácia 3 usou de uma mistura de excipientes (celulose microcristalina, talco, amido, aerosil, estearato de magnésio, lauril sulfato de sódio).

A celulose microcristalina pode ser usada como diluente, de forma a contribuir para melhorar o fluxo dos pós. Ela pode exercer outras funções na formulação como lubrificante, desintegrante e adsorvente. Por ser um excipiente quase insolúvel em água, o ideal é que seja utilizada com ativos altamente solúveis. Devido a essa insolubilidade, ela contribui para que o fármaco seja liberado de forma mais lenta. (Ferreira, 2010). Considerando que os Lactobacillus sp. são sensíveis ao pH gástrico e precisam chegar ao intestino em uma dose útil viável, o uso da celulose microcristalina pode contribuir para este fim.

O excipiente utilizado pela Farmácia 2 foi um frutooligossacarídeo, um prebiótico. Segundo Grumet, Tromp e Stiegelbauer (2020), para aumentar a estabilidade de produtos com probiótico, uma alternativa é usar aditivos como prebióticos e minerais. Em um estudo de comparação entre dois excipientes realizado por Liao et al., (2018) a viabilidade do probiótico foi maior quando foi usado o frutooligossacarídeo. Entretanto não foi isso que aconteceu como demonstrado anteriormente, na tabela 4. Na repetição ocorreu uma perda da viabilidade quando comparado ao primeiro ensaio.

Na farmácia 3 foi utilizada uma mistura de excipientes. Geralmente, para a encapsulação de pós, é utilizado uma mistura de adjuvantes com diversas funções, de forma que sejam compatíveis, nas quantidades adequadas. Os excipientes utilizados na Farmácia 3 possuem diversas funções. A celulose microcristalina já foi citada anteriormente. O talco farmacêutico atua como um absorvente contribuindo para reduzir a higroscopia. O amido é utilizado como diluente, o dióxido de silício coloidal atua como deslizante e absorvente. O estearato de magnésio é um lubrificante, contribui para reduzir a adesão dos pós na encapsuladoras. E por último, o lauril sulfato de sódio é um agente molhante, que favorece a desintegração e a dissolução de fármacos pouco solúveis (Ferreira, 2010).

Ao analisar a mistura de excipientes utilizada pela farmácia 3, também deve ser considerado as características do probiótico, que segundo o laudo dos fabricantes é altamente solúvel. Para ativos altamente solúveis, as classes de excipientes utilizadas devem ser lubrificantes, deslizantes e diluentes (Ferreira, 2010). Portanto, o agente molhante em cápsulas nem sempre pode ser uma boa escolha, favorecendo a desintegração da cápsula no estômago.

Além dos excipientes, o que mudou entre as farmácias foi o fornecedor dos probióticos. Cada uma das farmácias adquiriu o probiótico de fornecedores diferentes e isso também pode contribuir para a diferença encontrada nos três produtos. O tempo e forma de transporte desses microrganismos também pode ter influenciado, pois Segundo Ansel, Popovich e Allen (2013), o transporte da matéria prima é um aspecto importante, pois nesse transporte fatores como temperatura e umidade nem sempre são controlados, podendo a vir intervir na qualidade da matéria prima.

\subsection{Caracterização morfo-tintorial e testa da catalase}

Os resultados da prova da catalase e das características morfo-tintoriais do Lactobacillus $s p$ adquirido de diferentes farmácias de manipulação estão expressas na Tabela 6.

Tabela 6. Caracterização morfo-tintorial e prova da catalase das colônias de Lactobacillus sp.

\begin{tabular}{lll}
\hline Amostras & Caracterização morfo-tintoral das colônias & Prova da Catalase \\
\hline Farmácia 1 & Bacilo Gram negativo & Negativo \\
Farmácia 2 & Bacilo Gram negativo & Negativo \\
Farmácia 3 & Bacilo Gram negativo & Negativo \\
\hline
\end{tabular}

* Análise realizada com repetição.

Fonte: Autores. 
A literatura descreve que os Lactobacillus sp. apresentam-se em colônias de bacilos gram negativos com catalase negativa (Nazir, et al., 2019; Chamberlain, et al., 2019). Dessa forma, através dos resultados demonstrados anteriormente (Tabela 6), confirmou-se que o conteúdo das cápsulas adquiridas das Farmácias 1, 2 e 3 eram de Lactobacillus sp.

\section{Conclusão}

As farmácias magistrais de forma geral não atenderam a todos os critérios descritos na legislação, o mesmo acontece quando verificado a viabilidade dos probióticos encapsulados. Isso demonstrou que não há um controle de qualidade rigoroso quanto a manipulação de cápsulas contendo probiótico, comprometendo a qualidade e eficácia do produto. As farmácias magistrais precisam padronizar as cápsulas manipuladas com probióticos segundo sua concentração, prazo de validade e excipientes utilizados, a fim de garantir o melhor tratamento para o paciente.

Portanto, mais pesquisas acerca da qualidade de produtos magistrais com probióticos em cápsulas devem ser realizadas, bem como estudos que demonstrem os melhores excipientes a serem utilizados, de forma a contribuir cientificamente com soluções viáveis para este problema.

\section{Referências}

Allen Jr., L.V., Popovich, N G. \& Ansel, H. C. (2007). Formas Farmacêuticas e Sistemas de Liberação de Fármacos. (8a ed.), Artmed.

Andrade, D. F., Carvalho, J. S., \& Freitas, M. B. (2013) Qualidade de cápsulas de fluoxetina disponibilizadas pelo Sistema Único de Saúde: estudo in vitro das condições do ensaio de dissolução. Revista de Ciências Farmacêuticas Básica e Aplicada. 1-8.

Brasil. (2019). Agência Nacional de Vigilância Sanitária. Farmacopeia Brasileira. (6a ed). Anvisa, v.1.

Brasil. (2013). Agência Nacional de Vigilância Sanitária. Microbiologia Clínica para o Controle de Infecção Relacionada à Assistência à Saúde. Módulo 5: Fórmulas e produtos para provas de identificação laboratoriais.

Brasil. (2007). Agência Nacional de Vigilância Sanitária. Resolução RDC nº 67 de 08.10.2007: Boas práticas de manipulação de preparações magistrais e oficinais para uso humano em farmácia. Diário Oficial da União, Brasília.

Celandroni, F., Vecchione, A., Cara, A., Mazzantini, D., Lupetti, A., \& Ghelardi, E. (2019). Identificação de espécies de Bacillus: implicações na qualidade de formulações probióticas. PloS one. 14 (5), e0217021. https://doi.org/10.1371/journal.pone.0217021

Chamberlain, C. A, Hatch, M., \& Garrett, T. J (2019). Perfil metabolômico de probióticos de degradação de oxalato Lactobacillus acidophilus e Lactobacillus gasseri. PloS one, 14 (9), e0222393. https://doi.org/10.1371/journal.pone.0222393

Fenster, K., Freeburg, B., Hollard, C., Wong, C., Rønhave Laursen, R., \& Ouwehand, AC (2019). A produção e entrega de probióticos: uma revisão de uma abordagem prática. Microorganisms, 7 (3), 83. https://doi.org/10.3390/microorganisms7030083

Ferreira, A. (2010). Guia prático da farmácia magistral. v. 1, (4a ed.). Pharmabooks Editora.

Ferreira, A., \& Brandão, M. (2008). Guia prático da farmácia magistral. 2, (3a ed.). Pharmabooks Editora.

Grumet, L., Tromp, Y., \& Stiegelbauer, V. (2020) O desenvolvimento de formulações probióticas multiespécies de alta qualidade: do banco ao mercado. Nutrientes. 12 (8): 2453. https://doi.org/10.3390/nu12082453

Hill, C., Guarner, F., Reid, G., Gibson, G. R., Merenstein, D J., Pot, B., Morelli, L., Canani, R. B., Flint, H. J. \& Salminen, S. (2014) The International Scientific Association for Probiotics and Prebiotics consensus statement on the scope and appropriate use of the term probiotic. Nat Rev Gastroenterol Hepatol 11, 506514 (2014). https://doi.org/10.1038/nrgastro.2014.66

Jackson, A. S, Schoeni, J. L, Vegge, C., Pane, M., Stahl, B., Bradley, M., Goldman, V. S, Burguière, P., Atwater, J. B., \& Sanders, M. E. (2019). Melhorando a confiança do usuário final na qualidade dos produtos probióticos comerciais. Frontiers in microbiology, 10, 739. https://doi.org/10.3389/fmicb.2019.00739

Kim S. K., Guevarra R. B., Kim Y.T., Kwon J., Kim H., Cho J. H., Kim H. B., \& Lee J. H. (2019). Role of Probiotics in Human Gut Microbiome-Associated Diseases. J. Microbiol. Biotechnol. 29:1335-1340. https://doi.org/10.4014/jmb.1906.06064

Kolaček, S., Hojsak, I., Berni Canani, R., Guarino, A., Indrio, F., Orel, R., Pot, B., Shamir, R., Szajewska, H., Vandenplas, Y., van Goudoever, J., Weizman, Z., \& ESPGHAN Working Group for Probiotics and Prebiotics (2017). Commercial Probiotic Products: A Call for Improved Quality Control. A Position Paper. Journal of pediatric gastroenterology and nutrition, 65(1), 117-124. https://doi.org/10.1097/MPG.0000000000001603

Liao, N., Luo, B., Gao, J., Li, X., Zhao, Z., Zhang, Y., Ni, Y., \& Tian, F. (2019). Oligosaccharides as co-encapsulating agents: effect on oral Lactobacillus fermentum survival in a simulated gastrointestinal tract. Biotechnology letters, 41(2), 263-272. https://doi.org/10.1007/s10529-018-02634-6

Mazzantini, D., Calvigioni, M., Celandroni, F., Lupetti, A., \& Ghelardi, E. (2021). Spotlight on the Compositional Quality of Probiotic Formulations Marketed Worldwide. Frontiers in microbiology, 12, 693973. https://doi.org/10.3389/fmicb.2021.693973 
Morovic, W., Hibberd, A. A., Zabel, B., Barrangou, R., \& Stahl, B. (2016). Genotyping by PCR and High-Throughput Sequencing of Commercial Probiotic Products Reveals Composition Biases. Frontiers in microbiology, 7, 1747. https://doi.org/10.3389/fmicb.2016.01747

Nazir, Y., Hussain, S. A., Abdul Hamid, A., \& Song, Y. (2018). Probiotics and Their Potential Preventive and Therapeutic Role for Cancer, High Serum Cholesterol, and Allergic and HIV Diseases. BioMed research international, 3428437. https://doi.org/10.1155/2018/3428437

Oliveira, A. E., Hoffmann, L. C., Costa, M. P., \& Block, L. C. (2014) Análise e validação do procedimento de manipulação de cápsulas por encapsulamento manual por nivelamento. Revista de Ciências Farmacêuticas Básica e Aplicada, 35 (1): 59-65.

Pereira, A. S., Shitsuka, D. M., Parreira, F. J., \& Shitsuka, R. (2018). Metodologia da pesquisa científica. Santa Maria, RS: UFSM.

Schimitt, J. A. D., Fariña, L. O., Simões, M. R., \& Kottwitz, L. B. M. (2018). Evaluation of the Probiotic Profile of Lactobacillus Acidophilus Used in Pharmaceutical and Food Applications. Acta Scientiarum. Health Sciences (Online), 40, 1-9. https://doi.org/10.4025/actascihealthsci.v40i1.36664.

Shehata, H. R., Ragupathy, S., Shanmughanandhan, D., Kesanakurti, P., Ehlinger, T. M., \& Newmaster, S. G. (2019). Guidelines for Validation of Qualitative Real-Time PCR Methods for Molecular Diagnostic Identification of Probiotics. Journal of AOAC International, 102(6), $1774-1778$.

Terpou, A., Papadaki, A., Lappa, I. K., Kachrimanidou, V., Bosnea, L. A., \& Kopsahelis, N. (2019). Probiotics in Food Systems: Significance and Emerging Strategies Towards Improved Viability and Delivery of Enhanced Beneficial Value. Nutrients, 11(7), 1591. https://doi.org/10.3390/nu11071591

Thompson, J. E., \& Davidow, L. W. (2013). A prática farmacêutica na manipulação de medicamentos. (3a ed). Artrued.

Tripathi, N., \& Sapra, A. (2021). Gram Staining. StatPearls Publishing. https://pubmed.ncbi.nlm.nih.gov/32965827.

Troche, J. M. R., Adame, E. C., Díaz, M. Á. V., Escudero, O. G., Chávez, M. E. I., Barrera, J. A. C., Mondragón, F. Z., Velasco, J. A. V., Tavares, G. R. A. \& Pedrín, M. A. L. (2020). Lactobacillus acidophilus LB: a useful pharmabiotic for the treatment of digestive disorders. Therapeutic advances in gastroenterology, 13, 1756284820971201. https://doi.org/10.1177/1756284820971201

Vorländer, K., Kampen, I., Finke, J. H., \& Kwade, A. (2020). Along the Process Chain to Probiotic Tablets: Evaluation of Mechanical Impacts on Microbial Viability. Pharmaceutics, 12(1), 66. https://doi.org/10.3390/pharmaceutics12010066 